\title{
Da sala de aula para a rua ou da rua para a sala de aula? Os movimentos inesperados da vida na cidade e a relação com o saber escolar
}

\author{
From the classroom to the street or from the street \\ to the classroom? The unexpected movements of life \\ in the city and their relationship with school knowledge
}

Sandra Regina Ferreira de Oliveira*

\section{Resumo}

As aulas de campo são momentos potencializadores da aprendizagem e de algum modo relacionam-se com o cotidiano, o local e o tempo no qual se tecem as ações das mulheres e homens comuns na feitura diária da vida. O fato que deu origem a este artigo ocorreu durante uma aula de campo com alunos e alunas do $5^{\circ}$ ano na qual se estudava o patrimônio histórico em uma rua da cidade de Londrina. Na loja de artigos religiosos, as estátuas do Pai João e da Mãe Maria, que ali estão há mais de 30 anos, tempo significativo para uma cidade com 80 anos, chamaram a atenção de uma criança. O objetivo deste artigo é discutir os movimentos que se sucederam quando paramos em frente a tal loja para explicar as imagens.

Palavras-chave: ensino de história; afro-brasileiros; religiosidade.

\section{Abstract}

The field classes are enhancers of education and somehow relate to the everyday, the place and time in which the actions of ordinary women and men are weave in making daily life. The fact that gave rise to this paper occurred during a field class with students of the 5th year in which they studied about the historical heritage in a street of the city of Londrina. In a store of religious articles, the statues of Father John and Mother Mary, who are there for more than 30 years, what is significant for a city 80 years old, caught the attention of a child. The purpose of this article is to discuss the movements that followed when we stopped in front of the store to explain such images.

Keywords: teaching of history; AfricanBrazilians; religiosity.

Para Jorge Luis Borges (2007) não há um só homem que não seja um descobridor, e, em meio a tantas descobertas, nossas conclusões oscilam entre a dúvida e a fé e nos dão conta da própria ignorância. O que será apresentado

\footnotetext{
* Universidade Estadual de Londrina (UEL). sandraoliveira.uel@gmail.com
} 
nas páginas seguintes resulta do debruçar-se sobre um acontecimento na intenção de apontar os problemas percebidos quando, na escola, trabalha-se com temas relacionados à religiosidade afro-brasileira. Nesse processo, deparo com a complexidade das relações que sustentam a trama e identifico que também sou um fio que ajuda a manter presas, bem presas, determinadas tradições quanto ao que se ensina na escola e que não tem colaborado para ampliar a visão dos alunos sobre o mundo.

A ignorância, aqui compreendida como falta de conhecimento que é provocada, dentre outras coisas, pela limitação do que quero e me disponho a ver no e do mundo, provoca um efeito devastador quando nos colocamos à frente de várias crianças ou jovens com a função de ensiná-las sobre o mundo, tendo a cidade como referência. No entanto, a escuta atenta sobre as interpretações que as crianças fazem sobre o entorno conduz nosso olhar para outros cenários que olhos já viciados não buscariam. Javier Naranjo (2009), ao compilar e publicar as explicações de crianças colombianas para diversas palavras, expõe como elas são atentas aos diferentes aspectos da vida cotidiana e como estabelecem as mais variadas relações para construir os conceitos sobre todas as coisas. Foi pelo olhar de uma criança de 9 anos que a história deste texto começou.

\section{A SELEÇÃo DE CAMINHOS NA TENTATIVA DE ACERTAR}

No Projeto “As lentes captam o que o coração sente”, parte das ações do Programa Institucional de Bolsa de Iniciação à Docência (Pibid), ${ }^{1}$ propomos aos alunos e alunas do $5^{\circ}$ ano do Ensino Fundamental, com idades entre $9 \mathrm{e}$ 11 anos, estudar a temática Patrimônio Histórico a partir de alguns lugares da cidade. $^{2}$ A rua Sergipe foi um dos lugares escolhidos por três razões. Primeira: porque vivenciávamos, naquele contexto, uma alteração significativa em seu aspecto visual, com a retirada de banners e outdoors com vistas ao cumprimento da Lei Cidade Limpa (10.966/2010). Dessa forma, um novo cenário se apresentava aos olhos dos transeuntes que se dispusessem a olhar com mais vagar para o que ficou por décadas escondido pelas mais diversas propagandas e letreiros de lojas. Segunda: por se tratar de uma rua de comércio popular que é rota de acesso ao terminal central dos ônibus urbanos e frequentada pelos alunos e seus familiares que ali realizam compras, principalmente, de peças de 
vestuário e artigos diversos vendidos no espaço denominado "Camelódromo". Terceira: pelos estudos já realizados por diferentes pesquisadores sobre a rua e já publicados, fato que auxiliaria quanto à coleta de fontes e aprofundamento dos estudos sobre o local.

Elaboramos cuidadosamente todas as etapas do trabalho a ser desenvolvido em sala de aula pautando-nos em princípios pedagógicos que elegemos como importantes, como: (a) investigar o conhecimento prévio dos alunos e considerá-los no encaminhamento dos estudos; (b) definir os conceitos que seriam tratados em profundidade; (c) propor abordagens nas quais se fizesse necessária a generalização do que foi aprendido para outros contextos, e; (d) enfatizar uma abordagem metacognitiva incitando os estudantes a pensarem e explicitarem o seu processo de aprendizagem (Bransford; Brown; Cocking, 2007).

No tocante às especificidades do conhecimento histórico escolar, traçamos estratégias metodológicas com o intento de: (a) propiciar o desenvolvimento da imaginação histórica, recorrendo às diferenças existentes entre o que pode ser conhecido e o que é mera adivinhação; (b) priorizar o trabalho com fontes na elaboração de inferências sobre elas, e; (c) destinar amplo tempo para a construção e explanações interpretativas, orais e escritas, das crianças sobre o tema em questão (Cooper, 2012).

A esses aspectos aliaram-se outros princípios que auxiliam na compreensão das peculiaridades do conhecimento histórico. Dentre tantos que se dedicam ao tema, recorremos a Jörn Rüsen (2007) quanto às três dimensões que anuncia para o aprendizado histórico que, interligadas, culminam na formação histórica: (a) o aumento da experiência que leva à "distinção qualitativa entre passado e presente" (p. 111), compreendendo que o passado, de algum modo, permanece no presente, e que, ultrapassando o fascínio da comparação entre um e outro, possível muitas vezes pela constatação visual - quando, por exemplo, prédios antigos são rodeados por novas e modernas construções -, impulsiona para a elaboração de expectativas de futuro (p. 112); (b) aumento da competência interpretativa que confere sentido histórico aos saberes, a qual pode ser descrita como "a passagem de um dogmatismo quase natural das posições históricas (minha história - ou talvez também: a história do professor - é a única possível e verdadeira) à colocação do saber histórico em perspectiva, na qual a própria perspectiva pode ser demonstrada e até modificada argumentativamente" (Rüsen, 2007, p.115); (c) aumento da competência de 
orientação que se relaciona à capacidade de organizar e usar o conhecimento histórico (experiências e saberes) de forma a "organizar a vida prática, com sentido, em meio aos processos temporais, ao longo dos quais os homens e seu mundo se modificam" (Rüsen, 2007, p.116).

Consideramos também, ao planejarmos o trabalho com os alunos, os resultados obtidos na primeira fase do projeto de pesquisa "Histórias de Sucesso Pedagógico: outros olhares para o ensino e a aprendizagem na escola" (Hispep), ${ }^{3}$ em desenvolvimento desde o ano de 2010, os quais reafirmaram de forma contundente a importância que as atividades de campo, aqui entendidas como ações intencionalmente planejadas com vistas à aprendizagem de determinados saberes e que se diferem dos passeios recreativos, ${ }^{4}$ têm para o processo de aprendizagem. No projeto em questão perguntamos aos alunos e alunas do Ensino Médio (14 a 16 anos) e Ensino Fundamental (6 a 13 anos), de dez escolas públicas da cidade de Londrina, como aprendem melhor, e, dentre as mais de oito centenas de respostas recebidas, averiguamos como as saídas da sala de aula deixam marcas positivas e significativas quanto ao conteúdo aprendido, dentre outros aspectos.

As narrativas recebidas e que nos possibilitaram chegar a esta conclusão relacionam-se às diversas disciplinas do currículo escolar e descrevem com detalhes os lugares, a intencionalidade do trabalho e o que foi aprendido. As crianças e jovens, ao escreverem sobre essas ações, elaboram relações entre o que estudam na escola, o que identificam nos lugares visitados e, muitas vezes, em algo do trajeto, concretizando a aprendizagem por meio das generalizações e aplicação dos conceitos para outras situações, princípio pedagógico importante e já destacado neste artigo.

Pensar a escola para além dos seus muros e na relação com outros tantos espaços da cidade e do campo é, sem dúvida, primordial para empreitarmos as mudanças em prol de uma aprendizagem mais significativa para todos. Se, quando da invenção da escola moderna, os indivíduos buscavam na escola os saberes necessários para viver na sociedade, relacionados ao trabalho ou ao poder, atualmente identifica-se que os saberes que estão fora da escola são tantos e complexos que se faz necessária uma ampliação: a escola precisa selecionar dentre tantos saberes que compõem a contemporaneidade, científicos e não científicos, aqueles que precisam ser ensinados cientificamente. Em outras palavras, dissecados metodologicamente e pensados à luz de várias 
interpretações, de modo que possamos escolher para que lado queremos seguir quanto à aventura humana na terra. Nesse contexto, podemos citar os saberes, por exemplo, sobre o consumo e sobre qualquer tipo de discriminação, dentre tantas outras questões.

Silvia Alderoqui (2012) avança quanto à importância dos passeios urbanos para a construção do conhecimento. Quando eles relacionam-se a visitas educativas e excursões escolares, define-os por "passeios pedagógicos” (p.15). Em suas abordagens mais recentes sobre o assunto, aponta para outro tipo de passeio, propondo entender o caminhar pelas ruas da cidade como uma arte. Trata-se de:

perderse por las calles de la ciudad a la que se pertenece, no como elogio de la desorientación, sino con el sentido que tiene la palabra perderse para la infancia: perderse sin riesgos, perderse con seguridad, perderse con la imaginación para poder percibir a través de la contemplación, la literatura, la poesía, los símbolos y los sueños. (2012, p.16)

A partir do arcabouço teórico e metodológico destacado até então neste texto, compusemos a ação docente relacionada a "o quê" e "como" ensinar sobre a rua Sergipe para os alunos e alunas na escola e fora dela, nas aulas de campo, temas que receberam especial atenção quanto ao seu planejamento. Em uma dessas aulas, as crianças munidas de máquinas fotográficas registrariam os lugares mais significativos para cada um e, posteriormente, faríamos um roteiro de visita, em forma de folheto para divulgação na escola. O delineado pautava-se por uma caminhada pela rua, parando em alguns pontos anteriormente selecionados pela equipe de professores para pequenas explicações sobre diversos temas relacionados a tais lugares. Concebemos que os alunos teriam interesses próprios por pontos que não foram selecionados pela equipe e nos preparamos para valorizar essas escolhas, planejando parar sempre que um dos alunos indicasse algo como potente para compor nosso trabalho.

Em meio à caminhada pela rua Sergipe, o olhar de uma criança de 9 anos se perdeu de nosso roteiro e contemplou a imagem do Pai João e Mãe Maria ${ }^{5}$ em uma loja de artigos religiosos, a Loja Tupinambá. Assustada, perguntou: “o que é isso, professora?". Ao iniciar a explicação, fui interrompida pela professora da turma, que se aproximou e, em tom quase confidencial, expressou que seria melhor não adentrar "nesses assuntos", pois teríamos problemas com os 
pais. Minha reação foi de surpresa quanto à argumentação sobre o motivo apresentado para não avançarmos com as explicações, e recorri ao preconizado nas Leis 10.639/2003 e 11.645/2008 para legitimar e prosseguir com minha ação.

$\mathrm{Na}$ hora pensei em escrever um artigo sobre a posição da professora em relação à religiosidade afro-brasileira. O que conseguia ver, naquele contexto, era o preconceito dela. $\mathrm{O}$ meu estava tão arraigado nas minhas certezas que só foi descoberto meses depois, no processo de pesquisa para a escritura deste artigo. $\mathrm{O}$ que seria um artigo sobre limites dos professores transformou-se em um estudo acerca de nosso (ou meu) silenciamento sobre o outro.

\section{Ampliar EM Nós A CAPACIDADE DE OLHAR PARA A ALTERIDADE}

Bauman (2001, p.118) recorre a Claude Lévi-Strauss para explicar que na história humana, duas estratégias foram utilizadas quando se fez necessário enfrentar a alteridade: a forma antropoêmica, que consiste em colocar para fora, isolar, impedir o contato com o que é diferente; e a forma antropofágica, que se caracteriza pelo processo de tornar o outro igual a mim. A primeira aniquila o outro, a segunda aniquila sua alteridade. Concordando que continuamos a utilizar tais formas, o autor aponta como estratégias atuais antropoêmicas a "separação espacial, os guetos urbanos, o acesso seletivo a espaços e o impedimento seletivo a seu uso" (p.118). A assimilação forçada, que caracteriza a forma antropofágica, está presente nas "cruzadas culturais, guerras declaradas contra costumes locais, contra calendários, cultos, dialetos e outros 'preconceitos' e 'superstições'” (p.118).

O planejamento para o trabalho na rua Sergipe com as crianças foi cuidadosamente pensado, como já afirmei. Mas foi somente a partir da tentativa de recusa da professora em tratar das imagens relacionadas à umbanda que identifiquei os silenciamentos presentes na forma de tratar o que, até então, estava sendo entendido como importante e selecionado enquanto patrimônio histórico. O conceito de patrimônio histórico é aqui compreendido a partir das contribuições de Nestor Canclini (1999). Esse autor abarca sob o conceito de patrimônio as experiências vividas, linguagens e tradições imateriais como lendas, histórias e memórias do povo e que exacerbam a preservação física de lugares geralmente eleitos por alguns setores da sociedade que definem as memórias a serem mantidas. 
O primeiro movimento feito na tentativa de escrever este artigo voltou-se para os aspectos legais prescrito nas Leis 10.639/2003 e 11.645/2008, que tornam obrigatório o ensino da História e Cultura Afro-brasileira e Indígena, cotejados com a formação que os professores recebem, principalmente, nos cursos de Pedagogia, visto que se tratava de um trabalho desenvolvido junto às escolas que atendem os Anos Iniciais do Ensino Fundamental. No que se refere à proposta curricular do curso de Pedagogia da Universidade Estadual de Londrina (UEL), não há uma só disciplina que aborde, especificamente, quaisquer aspectos referentes à história da África ou às sociedades indígenas. A argumentação seria construída então a partir do não cumprimento da Lei, da formação que os professores recebem quanto ao assunto e das limitações que se fazem presentes na escola quando tais assuntos são trabalhados.

Foi imersa nesse processo que me perguntei: por que não incluímos a Loja Tupinambá nos lugares selecionados para serem estudados na rua Sergipe? Identifiquei em minhas lembranças que já havia visto, em outras aulas de campo, as crianças comentando entre si sobre as tais imagens. Por que não parei para explicar sobre elas?

Um acontecimento, ocorrido meses antes da aula de campo na qual vivenciei a solicitação direta da aluna, realizada em outubro de 2013, pode ter contribuído, assim como a preocupação explicitada pela professora, para o meu processo de tomada de consciência no trato da temática "religiosidade" com os alunos. No dia 2 de maio de 2013, uma quinta-feira, por volta das 13 horas, uma pessoa que se encontrava do outro lado da rua arremessou três pedras em direção às imagens, quebrando a cabeça e o braço do Pai João. Naquela ocasião, constatou-se que o autor da ação, um homem de aproximadamente 42 anos, apresentava problemas psicológicos. $\mathrm{O}$ ato recebeu amplo destaque na imprensa local, tanto pelo ocorrido como por se tratar do segundo caso de destruição de imagens religiosas ocorrido no estado em um curto período. Quatro dias antes, um homem tinha invadido a Catedral de Curitiba e destruído "uma cruz de Jesus Cristo, um quadro do papa João Paulo II, uma imagem de Santa Edwiges e um manto de Nossa Senhora Aparecida". Sobre tais acontecimentos, Elena Maria Andrei, pesquisadora do Núcleo de Estudos Afro-Asiáticos da UEL, indicou a intolerância religiosa presente e destacou que, frente às condições postas na pós-modernidade, tem-se acesso a muitas 
informações e, quando algo vai contra a verdade que cada um defende, torna-se uma ameaça frente à qual alguns reagem agressivamente. ${ }^{6}$

A Loja Tupinambá localiza-se na rua Sergipe há mais de 45 anos, e as imagens em questão foram ali colocadas há, aproximadamente, 30 anos. $\mathrm{O}$ local é de intenso movimento de pedestres e carros. O proprietário, sr. João Batista, ${ }^{7}$ relata que durante todos esses anos presenciou as mais variadas reações dos transeuntes em relação às imagens. Muitos se assustam porque, diante do seu tamanho, pensam tratar-se de duas pessoas reais. Passado o susto, alguns reagem de forma a manter distância, até mesmo atravessando a rua, outros olham de novo sem expressar nenhum preconceito, e há aqueles que voltam e colocam moedas na palma da mão de uma ou outra.

O sr. João Batista argumenta que, no passado, o preconceito com a loja era mais perceptível. Os habitantes da cidade, quando precisavam adquirir algum artigo, o que era muito comum, mandavam outras pessoas realizarem a compra, ou, quando eles mesmos compravam, faziam questão de explicar que estavam fazendo um favor a um amigo. Hoje, não há mais esse tipo de comportamento. A loja vende artigos destinados a várias religiões, e as pessoas entram, conversam, perguntam sobre os mais variados assuntos. Sobre o apedrejamento, compreende que se tratou de um caso isolado e destaca que foi confirmado o fato de o autor ter problemas psiquiátricos. Não houve ressarcimento dos prejuízos, e ele mesmo providenciou a restauração da imagem.

A Loja Tupinambá não é citada em nenhum material que utilizamos sobre a rua Sergipe e que serviu de base para o trabalho realizado na escola. ${ }^{8} \mathrm{~A}$ constatação desse fato só ocorreu meses depois do início da preparação deste artigo, quando mudei a perspectiva quanto ao estudo do problema. Assim, outros olhares aliaram-se ao meu quanto a "não se ver" a Loja Tupinambá e sua exuberância africana representada, principalmente, pelas imagens alocadas à sua porta. Um dos textos estudados na preparação da temática resultou do trabalho de sete pesquisadores que caminharam pela rua Sergipe e adentraram diferentes estabelecimentos comerciais, entrevistaram pessoas, moradores e comerciantes (Cesário et al., 2010). Sete sujeitos, sete olhares, e nenhuma referência à loja em questão.

Entender esses silenciamentos tornou-se o mote das reflexões apresentadas neste artigo: por que insistimos em não ver? A resposta para tal questão passa por muitos vieses, dentre os quais podem ser citados o nosso desconhecimento 
sobre a história da África e a dificuldade em abordar a religiosidade a partir de análises históricas e antropológicas.

Marina de Mello e Souza (2012) indica que o conhecimento sobre a história da África e das sociedades africanas auxiliaria na construção de uma abordagem a partir de "matrizes africanas e dos processos que lhes deram origem" (p.22), o que facilitaria o trato dos temas sobre os quais o preconceito é maior. Para a autora,

somente conhecendo bem as sociedades africanas, suas histórias e os processos que nos ligam a elas, assim como desvendando as noções por trás da construção histórica e ideológica dos preconceitos contra o africano e o negro, teremos condições de analisar com consistência as manifestações afro-brasileiras e o lugar que os africanos e seus descendentes ocuparam no passado e ocupam no presente, no contexto da sociedade brasileira como um todo. $(2012$, p.22)

Concordamos com a autora quanto às possibilidades que se abrem a partir de um conhecimento maior sobre a história da África. Durante décadas, a África foi apresentada aos estudantes brasileiros como celeiro de escravos, condição a partir da qual o negro adentrava a história do país. Longe de estarmos em um patamar confortável quanto à abordagem de tais temas nas escolas, muito se avançou a partir das conquistas dos movimentos engajados em tais lutas e da promulgação da Lei 10.639. Fato posto é que o conhecimento é um aspecto que impulsiona o olhar para outros cenários, outras possibilidades de conceber e explicar o que temos ao nosso redor.

A abordagem da temática "religiosidade" a partir dos aspectos históricos e culturais é outro aspecto que merece destaque. A Lei de Diretrizes e Bases 9394/96 e a Lei 9475/97 asseguram a diversidade, impedem a propaganda religiosa e proíbem, explicitamente, qualquer forma de proselitismo. No estado do Paraná, o Ensino Religioso, assim denominado em documento destinado aos professores dos anos iniciais do Ensino Fundamental, "implica alargar a visão e inserir atividades e conteúdos que contemplem as diferentes matrizes religiosas, a saber: nativas (indígenas - aborígines australianos) africanas, ocidentais, orientais e a negação da religião (ateísmo e agnosticismo)" (Schlögl, 2009, p.83).

O objetivo é levar o aluno a conhecer as mais diversas crenças, assim como o ateísmo e o agnosticismo. Na concepção do autor do documento "isto não 
significa a perda das próprias raízes e convicções, ao contrário, significa maior clareza de suas próprias opções” (Schlögl, 2009, p.95). Porém, não é dessa forma que pais e professores entendem. A professora que, durante nossa aula de campo, manifesta sua preocupação com uma possível reação dos pais, traduz uma situação crescente nas escolas: alguns pais não querem e não permitem que seus filhos conheçam temas ligados a religiões afro-brasileiras.

Júnia Sales Pereira e Luciano Magela Roza (2012) encontraram no estado de Minas Gerais reações semelhantes dos pais quanto ao trabalho nas escolas com temas referentes à história e cultura afro-brasileiras. Para os autores,

uma das mais fortes tensões deste período pode ser visualizada por meio da negativa de comunidades de pais e responsáveis, que se posicionam contrárias à introdução de conteúdos da história e da cultura africanas e afro-brasileiras nos currículos escolares. Motivadas por pressupostos morais e religiosos, essas comunidades expressam receio de que crianças e jovens estejam expostos a proselitismo religioso ao estudarem ou entrarem em contato com manifestações tradicionais africanas e afro-brasileiras. (2012, p.92)

Raquel Bakke argumenta que as religiões afro-brasileiras ocupam um papel importante no ensino, pois "como símbolos de resistência cultural, elementos dessas religiosidades, são mobilizados em livros, materiais didáticos escolares e no discurso de formadores e educadores" (2011, p.205). Entretanto, a resistência nas escolas quanto ao trabalho com tais temas é grande, e a autora argumenta que tal situação se constitui pelas concepções de alunos, pais e professores, que vinculam os símbolos das religiões afro-brasileiras à macumba, entendida aqui a partir da "carga negativa que esse termo carrega" (Bakke, 2011, p.206).

Ao comentar os resultados da pesquisa realizada por Bakke (2011), Marina de Mello e Souza (2012) argumenta que o tema "religiosidade" poderia aumentar a "dificuldade da implantação real da Lei 10.639" (p.21), e um caminho seria: "mudar o foco de interesse principal para outra esfera, que não a religiosa, e dessa forma introduzir conhecimentos que permitissem a construção de uma relação respeitosa com a alteridade representada pela cultura afro-brasileira" (Souza, 2012, p.21).

Encontrar um ponto confortável entre a necessidade de ensinar sobre a religiosidade na escola e, ao mesmo tempo, garantir o respeito às escolhas 
familiares, não é tarefa fácil. Compreender quando ocorre proselitismo religioso e cultural pode ser um caminho. Júnia Sales Pereira e Luciano Magela Roza (2012) indicam que ele ocorre

quando, no estudo de uma manifestação, temática ou assunto, o professor supõe estarem os alunos postos diante de um modo de vida, de uma verdade ou de um conjunto de crenças a serem assimilados como normativos ou mais recomendáveis. Ao invés de uma postura investigativa, o que essa abordagem favorece - e, em alguma medida exige - é uma adesão. Comumente associa-se ao proselitismo o solipsismo, que é uma postura que supõe ser a verdade de uma pessoa ou grupo, ou de um professor, a única verdade passível de aceitação e confirmação - a verdade de uma pessoa é compreendida como a única forma de verdade vigente, e somente são consideradas as experiências orientadas por essa verdade. (2012, p.104)

Conhecer a forma de viver do outro, o que inclui a religiosidade, é o primeiro ponto para que esse outro ocupe espaço no meu campo de visão. O que impediu a presença dos afro-brasileiros nas histórias contadas sobre a rua Sergipe, assim como nas ações que planejamos para desenvolver o projeto "As lentes captam o que o coração sente" junto aos alunos, foi o desenho mental que temos da rua e dos que nela trabalham e vivem. Bauman (2001) explica que cada habitante da cidade elabora um mapa em sua cabeça, o qual é composto pela leitura subjetiva do espaço. São mapas diferentes resultantes do conhecimento que se tem do espaço no qual se vive. Determinados lugares não existem para determinadas pessoas porque a referência para leitura do espaço passa pelo crivo do que seleciono para ver. Essa seleção é construída a partir de registros que coletamos no processo educativo familiar, religioso e escolar no qual alguns grupos são colocados em evidência e outros são segregados. Não vemos por que nos ensinaram o que deve ser ou não visto. Assim, "o vazio do lugar está no olho de quem vê e nas pernas ou rodas de quem anda. Vazios são os lugares em que não se entra e onde se sentiria perdido e vulnerável, surpreendido e um tanto atemorizado pela presença de humanos" (Bauman, 2001, p.122). Se nos preocuparmos em educar o olhar para uma leitura mais plural do mundo, certamente comporíamos outros mapas da cidade, marcados pela diversidade de cores, sons, cheiros; compostos por diferentes formas de organização, por pessoas que entendem o mundo de forma diversa e, assim, 
poderíamos nos perder pelas ruas da cidade, no sentido apresentado por Alderoqui (2012). Perder-se para, nesse caso, encontrar-se com o outro.

Romina Ramírez (2013), em seus estudos sobre biografias de jovens, discute a importância e a influência que o bairro, a igreja e a escola têm na sua formação. Depois de ouvir muitos deles, habitantes de bairros populares, expõe como o que aprendem nesses espaços é determinante para a compreensão do entorno, inclusive para a inserção desses jovens em outros espaços da cidade. Os jovens estabelecem relações entre os conhecimentos que advêm de lugares diversos e com status diversos. No bairro, os lugares são múltiplos e todos que por ali transitam, de uma forma ou outra, ensinam algo. Nas igrejas, os ensinamentos estão vinculados a dogmas que servem de pano de fundo para a elaboração de interpretações do que se vivencia na sociedade. Muitas vezes, a definição do certo e do errado, do que deve ser ou não contemplado, aceito ou excluído, é ditada por esses dogmas. A escola, fechada em um ensino pautado em propostas curriculares que não dialogam com o entorno e com os problemas contemporâneos, pouco contribui para o processo formativo de tais jovens, embora eles, conforme Ramírez (2013), confiem a essa instituição um lugar de destaque em seu processo formativo. Mas se trata de uma formação para depois, para um futuro que pode ou não chegar. Não se trata de uma formação para que o jovem possa se entender no mundo de hoje.

Essas reflexões me remetem a pensar sobre as mudanças possíveis na escola se ampliarmos o conceito do que compõe o currículo escolar de forma a abarcar temas e problemas que, por causarem desconforto a alguns, são retirados do rol dos conteúdos a serem ensinados. Paralelamente, se faz importante avançar dia após dia na direção de compreender as escolhas que, enquanto professores, efetuamos ao ensinar. Para além de compreender sobre os conteúdos que elegemos ensinar, recomenda-se perguntar sobre os assuntos que deixamos de tratar. Que silêncios tenho imposto aos meus alunos? Quem está sendo silenciado? Por quais espaços da cidade não transito e não levo meus alunos a transitarem?

Tais questões não são fáceis de fazer para nós mesmos e, não raro, elaboramos respostas pautadas somente nas nossas verdades, o que não nos leva a lugar algum. Mas no meio do caminho, às vezes, encontramos uma criança curiosa que faz aflorar em nós um realismo esperançoso, conforme define Ariano Suassuna. A criança vê e pergunta. A professora, com medo dos pais, 
tenta esquivar-se da resposta. Eu, em meio a esse movimento, fico indignada com a reação da professora e demoro meses para compreender que o medo dela e o posicionamento dos pais são situações geradas e alimentadas também pela forma como me posiciono no mundo.

\section{CONSIDERAÇÕES FINAIS}

Em frente à Loja Tupinambá respondo à criança:

- O que é isso, professora?

- É um Pai e uma Mãe de Santo. Vocês sabem que são diversas as religiões, não sabem? Em coro:

- Sabemos.

- Quem aqui é católico? Dedos levantam.

- Quem é evangélico? Dedos levantam.

- Quem é da umbanda? Dedos não levantam e escuto uma voz que não identifico, se vem da professora ou de uma das mães que acompanham a aula de campo: ${ }^{9}$

- Ai, meu Deus.

- Quem é do Candomblé? Dedos não levantam.

- Quem é espírita? Dedos não levantam, mas um aluno grita:

- Minha vó vai no centro espírita, mas ela é católica também. Muitas vozes ao mesmo tempo:

- Minha vó também. A minha também. Muitas falas. Todos têm uma história para contar e comentam com o colega do lado.

- Pois é. Em nosso país tem muito disso.

- Quem aqui é ateu? Caras de desconhecimento. Explico o que é. Nenhum dedo levantado. Chamo a atenção para a cabeça do Pai João, que depois de restaurada destoa um pouco do restante da imagem.

- Vocês estão vendo a cabeça dele? O que acham que aconteceu? Uma aluna responde:

- Quebraram.

- Isso mesmo. Jogaram uma pedra e quebrou.

- O que significa isso para a gente? Outra aluna:

- Racismo. 
- Também significa racismo. Mas também significa preconceito religioso. Faço tal comentário em resposta à postura da professora que não queria parar para responder a aluna.

- E significa outra coisa ainda: se essa imagem não estivesse aqui, poderíamos estar parados conversando todos estes assuntos? Em coro:

- Não.

- Então. Por que não podemos destruir? Em coro:

- Porque é um patrimônio histórico.

- Nem tudo precisa ser "oficial” para ser um patrimônio histórico. É o máximo que consigo falar na tentativa de explicar sobre a importância de outras leituras sobre o que vem a ser eleito à categoria de patrimônio histórico. Outra criança interrompe e aponta com o dedo para as mãos do Pai João e Mãe Maria, nas quais estão algumas moedas.

- O que é isso aqui?

- Algumas pessoas acreditam que oferecendo essas moedas para eles a vida vai melhorar, ou colocam para agradecer por alguma coisa. Qual a sua religião?

- Católica.

- Então, quando o coroinha passa recolhendo as oferendas...

- Eu sou coroinha...

- Você não recolhe as oferendas?

- Recolho.

- Então, são formas diferentes de fazer coisas bem iguais. Essas imagens aqui representam um tipo de religiosidade dentre as tantas que a gente tem em nosso país. Querem ver mais de perto? A professora fala:

- Vamos andando, pessoal. Pergunto ao dono da loja se podemos entrar. Ele autoriza. Explico aos alunos que os que quiserem podem entrar. Todos entram. As mães também. A professora fica esperando os alunos na porta. Uma mãe fala para mim:

- Eu nunca reparei nisso aqui. Aponta para as imagens. Minha orientanda de mestrado, que está filmando, comenta:

- É olhar histórico.

- É mesmo - responde a mãe. 
Hoje, revendo as imagens do vídeo, percebo claramente que ao parar em frente à loja para comentar o fato, detive-me na ação, no vandalismo, no estrago feito a algo e não, propriamente, no significado que aquela ação estabelecia em relação ao preconceito religioso com as crenças cujas origens remetem aos povos africanos e seus descendentes. Identifiquei, então, que o problema não era somente com a professora que verbalizou o medo de entrar em conflito com alguns pais que não querem que seus filhos estudem temáticas relacionadas à umbanda ou ao candomblé. O problema também era o que foi eleito à categoria de saber escolar, portanto, indicado para ser ensinado às crianças na escola.

Finalizo este texto em setembro de 2014, meses depois de iniciá-lo. Que bom que demorei tanto para fazê-lo. Se tivesse terminado antes, o resultado seria uma abordagem sobre os limites do professor, caminho sempre percorrido quando se trata de pensar os problemas da escola. Porém, todos têm sua parcela de responsabilidade na educação do olhar de todos para as questões sociais. Aqueles que se dedicam à educação assumem essa responsabilidade como ofício.

O mal, representado nas mais variadas figuras, é alimentado também pelos nossos silenciamentos que excluem temáticas do rol que delimitamos como saberes escolares. A religiosidade tem sido constantemente excluída. Ações extremas, como o apedrejamento de imagens por pessoas com desequilíbrio psicológico, nos chamam a atenção, mas outras ações discriminatórias acontecem cotidianamente, provocadas pela concepção de que a minha forma de ver o mundo é a verdadeira.

Todos nós que silenciamos frente à diversidade, que evitamos ensinar para os pequenos a multiplicidade que compõe os seres humanos, a sociedade, as religiões e tantos outros conceitos importantes para se compreender e agir no mundo. De forma indireta, empunhamos a faca que matou, em agosto de 2013, Ya Mukumby, dona Vilma, mulher, negra, líder no movimento negro em Londrina. $\mathrm{O}$ ato foi protagonizado também por um homem com problemas psicológicos. A loucura não é somente daquele que rompe com as barreiras dos limites necessários para se viver em sociedade. A loucura é de todos nós que, por silenciarmos, gritamos a todos o que deve ser entendido como o mal, o incorreto e o anormal. 


\section{REFERÊNCIAS}

ALDEROQUI, Silvia. Paseos urbanos: el arte de caminar como práctica pedagógica. Buenos Aires: Lugar Editorial, 2012.

BAKKE, Raquel Rua Baptista. Na escola com os orixás: o ensino das religiões afro-brasileiras na aplicação da Lei 10.639. Tese (Doutorado) - Programa de Pós-Graduação em Antropologia Social, Departamento de Antropologia, FFLCH, USP. São Paulo, 2011.

BAUMAN, Zygmunt. Modernidade líquida. Trad. Plínio Dentzien. Rio de Janeiro: Jorge Zahar, 2001.

BORGES, Jorge Luis. Ficções. Trad. Davi Arrigucci Jr. São Paulo: Companhia das Letras, 2007.

BRANSFORD, John D.; BROWN, Ann L.; COCKING, Rodney R. (Org.) Como as pessoas aprendem: cérebro, mente, experiência e escola. Trad. Carlos David Szlak. São Paulo: Ed. Senac, 2007.

CANCLINI, Nestor Garcia. Los usos sociales del patrimonio cultural. In: CRIADA, E. A. (Coord.) Patrimonio Etnológico: nuevas perspectivas de estúdio. Andalucia: Junta de Andalucia/Consejería de cultura/Instituto Andaluz Del Patrimono Historico; Editorial Comares, 1999. p.16-33.

CESÁRIO, Ana Cleide Chiarotti et al. Sergipe, a rua de todas as compras. In: MAGALHÃES, Leandro H. (Org.) Rua Sergipe: patrimônio cultural londrinense. Londrina, PR: Ed. UniFil, 2012.

COOPER, Hilary. Ensino de História na educação infantil e anos iniciais: um guia para professores. Trad. Rita de Cássia K. Jankowski, Maria Auxiliadora M. S. Schmidt, Marcelo Fronza. Curitiba: Base Editorial, 2012.

NARANJO, Javier. Casa de las estrellas: el universo contado por los niños. Bogotá: Aguilar, 2009.

OLIVEIRA, Sandra Regina Ferreira de; LUGLE, Andreia M. C.; AGUIAR, Beatriz C. Lima (Org.) O Movimento da Ação Docente no Ensino Fundamental I. Londrina, PR: UEL, 2013.

PEREIRA, Júnia Sales; ROZA, Luciano Magela. O ensino de história entre o dever de memória e o direito à história. Revista História Hoje, São Paulo: Anpuh, v.1, n.1, p.89-110, jun. 2012. Disponível em: http://www.anpuh.org/revistahistoria/ view?ID_REVISTA_HISTORIA $=15$

RAMÍREZ, Romina. El barrio, la iglesia e la escuela: instituciones donde los jóvenes construyen sus biografias. In: DI LEO, Pablo Francisco; CAMAROTTI, Ana Clara. "Quiero escribir mi historia": vidas de jóvenes en barrios populares. Buenos Aires: Biblos, 2013. p.69-86.

RÜSEN, Jörn. História viva: formas e funções do conhecimento histórico. Trad. Estevão de Rezende Martins. Brasília: Ed. UnB, 2007. 
SCHLÖGL, Emerli. Ensino Religioso. In: AMARAL, Arleandra Cristina Talin (et al.) (Org.) Ensino Fundamental de nove anos: orientações pedagógicas para os anos iniciais. Curitiba: Secretaria de Estado da Educação, 2010. p.83-98.

SOUZA, Marina de Mello e. Algumas impressões e sugestões sobre o ensino de história da África. Revista História Hoje, São Paulo: Anpuh, v.1, n.1, p.17-28, jun. 2012. Disponível em: http://www.anpuh.org/revistahistoria/view?ID_REVISTA_HISTORIA $=15$

\section{NOTAS}

${ }^{1}$ Projeto financiado pela Coordenação de Aperfeiçoamento de Pessoal de Nível Superior (Capes).

${ }^{2}$ Sobre os resultados do projeto, ver: OLIVEIRA; LUGLE; AGUIAR, 2013, p.17-26.

${ }^{3}$ Projeto financiado pelo Conselho Nacional de Desenvolvimento Científico e Tecnológico (CNPq).

${ }^{4}$ Os passeios recreativos são aqui entendidos como ações importantes na escola cuja finalidade é promover a socialização entre os alunos, o que não elimina as muitas e variadas aprendizagens possíveis em sua decorrência. O que difere o passeio da aula de campo é a intencionalidade pedagógica que, presente em ambos, na segunda volta-se mais para a aprendizagem de um saber conceitual e relacionado a uma área do conhecimento, por isso é organizada pelo professor de forma mais diretiva.

${ }^{5}$ Os nomes "Pai João" e "Mãe Maria", utilizados pelo proprietário da loja para se referir às imagens, foi mantido.

${ }^{6}$ Disponível em: FolhaWeb, 3 maio 2013; www.folhaweb.com.br/?id_folha=2-1--28120130503; Acesso em: 7 set. 2014.

${ }^{7}$ Entrevista concedida à autora do artigo, por telefone, em abril de 2014.

${ }^{8}$ Registra-se que um dos autores com os quais trabalhamos no projeto, dr. Leandro Henrique Magalhães, realizou no ano de 2007, com outras pessoas, um estudo sobre a diversidade religiosa em Londrina e produziu o folheto Roteiro da Diversidade Religiosa da Cidade de Londrina. Nele estão contemplados igrejas evangélicas e católicas, mesquitas, templos budistas, terreiros e centro espíritas. O material encontra-se disponível em www.educacaopatrimonial.com.br/\#roteiros/02.html.

${ }^{9}$ É comum na escola em questão os professores solicitarem ajuda dos pais para acompanharem os grupos de alunos em atividades fora da escola. No dia em questão, contamos com a ajuda de três mães.

Artigo recebido em 24 de setembro de 2014. Aprovado em 23 de outubro de 2014. 